\title{
PREVALÊNCIA DO ALCOOLISMO EM FEIRANTES
}

\author{
Guilherme de Jesus Santos ${ }^{1}$; Tania Maria $\operatorname{Costa}^{2}$ e Davi Martins Fêlix Júnior ${ }^{3}$.
}

\footnotetext{
1. Bolsista PROBIC/UEFS, Graduando em Enfermagem, Universidade Estadual de Feira de Santana, Membro do Núcleo de Estudos e Pesquisas Sobre o Cuidar/Cuidado - NUPEC, e-mail: guilherme.jsantos@ outlook.com

2. Orientador, Departamento de Saúde, Universidade Estadual de Feira de Santana, Membro do Núcleo de Estudos e Pesquisas Sobre o Cuidar/Cuidado - NUPEC, e-mail: tmctaniacosta@gmail.com

3. Co-orientador, Departamento de Saúde, Universidade Estadual de Feira de Santana, e-mail: dmartins2006@ gmail.com.
}

\section{PALAVRAS-CHAVE: alcoolismo; promoção a saúde; feirantes.}

\section{INTRODUÇÃO}

O uso de bebidas alcoólicas é um comportamento que varia de acordo com a cultura de cada povo; o consumo pode estar associado a diversos fatores e situações, como festejos comemorativos, eventos culturais, cerimônias religiosas, sucesso em negócios, reuniões de amigos; assim como problemas psicossociais. Contudo, nos dias de hoje o alcoolismo é um dos mais sérios problemas de saúde pública, chamando atenção de distintas áreas do conhecimento, assim como do estado.

Quanto ao consumo de bebidas alcoólicas, Andrade; Anthony e Silveira (2009), assinalaram a tendência crescente do seu consumo no mundo ao descreverem, que a cada ano, cerca de 2 bilhões de pessoas consomem bebidas alcoólicas, o que corresponde a aproximadamente $40 \%$ (ou 2 em cada 5) da população mundial acima de 15 anos.

No Brasil, em média, são consumidos 8,7 litros de álcool puro per capita a cada ano, comparativamente a média global de 6,2 (seis vírgula dois) litros (Organização Mundial de Saúde - OMS, 2014); quanto às consequências do uso habitual de bebidas alcoólicas, segundo Brites e Abreu (2014) há dez anos, o uso nocivo de álcool foi responsável por 3,8\% do índice de mortalidade mundial.

O "beber em binge" implica diversos problemas de ordem bio-psicosocial, como a violência (doméstica, homicídios, roubo), os acidentes (de carro, quedas, afogamentos) e pode relacionar-se a doenças cardiovasculares (cardiomiopatia alcoólica, hipertensão arterial sistêmica, doença arterial coronariana) e acidente vascular cerebral.

Já no ambiente de trabalho, sabe-se hoje que a ingestão de bebidas alcoólicas é um forte agravante para acidente de trabaho (AT), pois ela agindo no Sistema Nervoso Central (SNC) de forma depressiva, causa sonolência, redução da atenção e da concentração, lentidão do pensamento e dos reflexos e certa dificuldade de coordenação motora (NEVEZ; MEIRELLES, 2014), assim pode propiciar diversos acidentes de trabalhos, assim como outros prejuízos, a 
exemplo, diminuição na produtividade e no lucro, absenteísmo, perda da mercadoria, para comerciantes de produtos, em especial os pequenos, como os feirantes.

Assim, o presente estudo será norteado pelas seguinte questão: Qual a prevalência do alcoolismo em feirantes? Tendo como objetivos: Definir a prevalência de alcoolismo nos feirantes do Centro de Abastecimento de Feira de Santana Feira de Santana - BA e Identificar casos de uso abusivo de bebidas alcoólicas nos feirantes que trabalham no Centro de Abastecimento de Feira de Santana, Feira de Santana - BA.

\section{METODOLOGIA}

Trata-se de um estudo quantitativo, de corte transversal, descritivo e exploratório. O campo da investigação foi o Centro de Abastecimento de Feira de Santana - CAF, inaugurado em 10 de janeiro de 1977, localizado no Loteamentos Parque Leal Mathias em pleno o centro da cidade; os informantes foram feirantes de18 a 72 anos de idade, de ambos os sexos, que atuam no CAF, há pelo menos seis meses e no mínimo três vezes na semana. A amostra foi de 116 feirantes dos seguintes setores: hortifrúti, cereais, carnes, laticínios, condimentos, frutos do mar, alumínios/ferragens e artesanatos, sendo a maior concentração deles no setor de hortifrúti; Os dados do tipo primários foram coletados, através de um questionário específico para o rastreamento do uso de álcool, o Alcohol Use Disorders Identification Test - AUDIT que leva em consideração as variáveis quantidade e frequência referentes ao consumo no último ano, sua pontuação varia de zero a 40, classificando os participantes da pesquisa em: consumo de baixo risco ou abstinência ( 0 a 7 pontos), uso de risco ( 8 a 15 pontos), uso nocivo (16 a 19 pontos) e provável dependência (20 ou mais pontos) (NEVES; MEIRELLES, 2014).

A coleta foi realizada nos meses de junho/julho de 2018, pelo autor e equipe anteriormente treinada. A aproximação com os feirantes se deu através da realização de feira de saúde itinerante, desde a época de voluntário do NUPEC. Os dados coletados foram organizados no Excel e explorados com auxílio do programa estatístico Statistical Package for the Social Science (SPSS). Para descrever e sintetizar esses dados, usamos a estatística descritiva, através da distribuição de frequência absoluta e relativa. Logo em seguida foram realizadas analises e discussões apoiadas na revisão de literatura construída.

A proposta do estudo foi submetida ao Comitê de Ética em Pesquisa com Seres Humanos da Universidade Estadual de Feira de Santana (CEP-UEFS), sendo aprovada com o parecer de número 2.642.426.

\section{RESULTADOS E DISCUSSÃO}


Os informantes do estudo foram 116 feirantes que trabalham no CAF, de diferentes setores, tais como, artesanatos, laticínios, cereais, pescados - camarão e peixe e outros. Desses setores destacou-se com maior percentual, feirantes o de hortifruti $(37,1 \%)$ seguidos dos que revendem carnes $(24,1)$ e dos que negociam cereais $(17,2 \%)$.

Quanto aos caracteres dos informantes, em relação ao sexo a distribuição foi equitativa, isto é, $50 \%$ em ambos os sexos. Em relação a idade, foi observado variação de 18 a 78 anos, com maior concentração de informantes entre 36 a maior de 56 anos de idade; na situação conjugal, houve uma predominância de casados (45,7\%); quanto a cor/etnia, 83,6\% se autodeclararam negros. O nível de escolaridade variou de indivíduos analfabetos ou semianalfabetos ao nível superior concluído ou em andamento, entretanto a predominância foi de ensino médio concluído, com $43,1 \%$. No que se refere a renda mensal a maioria dos feirantes informou renda de menos de um salário mínimo a dois salários mínimos.

Em conformidades com os padrões do AUDIT, 70,7\% dos feirantes estão no padrão de consumo de baixo risco, $19 \%$ no uso de risco para bebidas alcoólicas, 5,2\% em um uso nocivo, e $5,2 \%$ uma provável dependência. Dados que corroboram com estudo de Verardino e Zerbetto (2014). Acredita-se que essa situação esteja relacionada a vulnerabilidade vivenciada pelos feirantes e o estresse psicossocial.

Neste sentido Vidal, Abreu e Portela (2017) salientam que o estresse psicossocial mostrou-se significativamente associado ao consumo de risco de bebidas alcoólicas, desse modo, indivíduos com alto estresse no trabalho teriam aproximadamente 3 vezes mais chances de apresentar padrão de uso de risco quando comparados aos trabalhadores submetido a menor estresse.

Considerando que a ingestão de bebida alcoólica é progressiva, salienta-se as intervenções necessárias conforme os padrões de consumo; assim, para o consumo de baixo risco, educação em saúde visando a descontinuação ou manutenção do padrão de uso atual; no uso de risco, orientação básica salientando os possíveis riscos orgânicos, psicológico ou sociais que a manutenção de consumo pode gerar; no uso nocivo é necessário a utilização da intervenção breve, com orientação e monitoramento, que visa a diminuição da ingestão de bebidas alcoólicas e dos possíveis danos relacionados a esta; na provável dependência, encaminhamento a serviço especializado para diagnóstico e acompanhamento (CARNEIRO et al., 2017).

\section{CONCLUSÃO}

O consumo de bebidas alcoólicas pode evoluir progressivamente, implicando a doença alcoolismo que é crônica, acarretando danos de ordem física e psicossocial. Então a situação identificada nos feirantes, requer atenção. Assim, em nossa realidade os feirantes dos padrões de 
baixo risco e uso de risco poderiam ser acompanhados e monitorados pelos profissionais da Equipe de Saúde Família (ESF) de sua referência, conjuntamente com os profissionais do Núcleo Ampliado de Saúde da Família (NASF), evitando o agravamento da situação. E aqueles de padrões de uso nocivo e provável dependência seriam referenciados pelos profissionais da ESF para serviços especializados, Centro de Atenção Psicossocial - Álcool e Drogas (CAPS-AD), e posteriormente contra-referenciados para a Unidade de Saúde da Familia (USF) de origem a qual com o apoio do NASF dariam um suporte contíguo aos feirantes e aos seus familiares, apesar das dificuldades vivenciadas nas USF.

Nas feiras livres deve-se manter os trabalhos educativos visando a informar sobre o alcoolismo e os danos a saúde, decorrentes dele, através de, radionovelas no sub-projeto "Saúde nas Ondas do Rádio" (AGUIAR; COSTA; SANTOS, 2011), teatro de fantoches, distribuição de materiais educativos (cartilhas, panfletos, folders) e distribuição de água aos feirantes, essa objetivando a redução de danos.

\section{REFERÊNCIAS}

AGUIAR, M. G .G.; COSTA, T. M.; SANTOS, C. L. R. Promovendo a saúde no cotidiano das feiras livre de Feira de Santana - BA. 2011. 26f. (Projeto de Extensão). Núcleo de Pesquisas e Estudos sobre o cuidar/Cuidado (NUPEC). Universidade Estadual de Feira de Santana.

ANDRADE, A. G; ANTHONY J. C; SILVEIRA, C. M. Álcool e suas consequências: uma abordagem multiconceitual. Barueri, SP: Minha Editora, 2009.

BRITES, R. M. R.; ABREU, A. M. M. de. Padrão de consumo de bebidas alcoólicas entre os trabalhadores e perfil socioeconômico. Acta Paul Enferm., São Paulo, v. 27, n. 2, p. 93-99. 2014. Disnponivel em: < http://www.scielo.br/pdf/ape/v27n2/0103-2100-ape-27-02-0093.pdf >. Acesso em: 20 mar 2018.

CARNEIRO, A. P. L. et al. AUDIT \& AUDIT-C. Ministério da Justiça - Secretaria Nacional de Políticas Sobre Drogas, Brasília, DF, 2017. . Disponível em:

<http://www.aberta.senad.gov.br/medias/origina1/201704/20170424-095653-001.pdf >. Acesso em: 30 jul 2018.

NEVES, E. E. D. MEIRELLES, M. A. L. O uso do AUDIT na identificação e estratificação do alcoolismo no contexto da atuação do fisiote rapeuta: uma revisão literária. 2014, $44 \mathrm{f}$. Trabalho de Conclusão de Curso (Bacharelado em Fisioterapia), Universidade Federal de Juiz de Fora, Juiz de Fora MG.

VERARDINO, R. G. S. ZERBETTO, S. R. Padrão do uso de álcool por usuários de uma Unidade de Saúde da Família. Cad. Ter. Ocup, São Carlos, v. 22, n. 1, p. 27-35, 2014. Disponível em: <http://www.cadernosdeterapiaocupacional.ufscar.br/index.php/cadernos/article/view/789/508>. Acesso em: 27 jul 2018.

VIDAL, J. M.; ABREU, A. M; PORTELA,L. F. Estresse psicossocial no trabalho e o padrão de consumo de álcool em trabalhadores offshore. Cad. Saúde Pública, Rio de Janeiro, v. 33, n. 6, p. 1-7, 2017. Disponível em: <https://www.scielosp.org/pdf/csp/2017.v33n6/e00116616>. Acesso em: 9 jul 2018. 